\title{
Efficient in situ Regeneration of NADH Mimics by an Artificial Metalloenzyme
}

\author{
Yasunori Okamoto, ${ }^{\dagger}$ Valentin Köhler, ${ }^{\dagger}$ Caroline E. Paul, ${ }^{\dagger}$ Frank Hollmann, ${ }^{\star}$ and Thomas R. Ward ${ }^{\dagger *}$ \\ 'Department of Chemistry, University of Basel, Spitalstrasse 51, CH-4056 Basel, Switzerland \\ ${ }^{\star}$ Department of Biotechnology, Delft University of Technology, Julianalaan 136, 2628BL Delft, The Netherlands
}

\begin{abstract}
NADH mimics (mNADHs) have been shown to accelerate and orthogonally activate ene reductase-catalyzed reactions. However, existing regeneration methods of $\mathrm{NAD}(\mathrm{P}) \mathrm{H}$ fail for mNADHs. Catalysis with artificial metalloenzymes based on streptavidin (Sav) variants and a biotinylated iridium cofactor enable the mNADHs regeneration with formate. This regeneration can be coupled with ene reductase-catalyzed asymmetric reduction of $\alpha, \beta$-unsaturated compounds, due to the protective compartmentalization of the organometallic cofactor. With $10 \mathrm{~mol}^{\%} \mathrm{mNAD}^{+}$, a preparative scale reaction $(>100 \mathrm{mg})$ gave full conversion with $98 \%$ e.e, where TTNs reached 2000 with respect to the Ir cofactor under ambient atmosphere in aqueous medium.
\end{abstract}

\section{KEYWORDS. Artificial metalloenzyme, iridium, biocatalysis, renewable source, asymmetric catalysis}

The increasing industrial use of biocatalytic processes can by-and-large be traced back to the high chemo-, regio-, and enantioselectivity of engineered enzymes. ${ }^{1-7}$ These features enable low priced products thanks to high space time yields, reduced separation expenditures and waste formation. Oxidoreductases are firmly established as valuable tools for synthetic chemistry purposes. However, more than 400 enzymatic redox reactions require relatively costly pyridine nucleotide cofactors $\mathrm{NAD}(\mathrm{P}) \mathrm{H}$ as redox equivalents, typically in combination with an enzymatic recycling system. ${ }^{8-10}$

Various synthetic NAD(P)H mimics (mNADHs) have been synthesized for various purposes including: i) mechanistic probes, ${ }^{11-13}$ ii) a decrease in the relatively expensive operational costs of NAD $(\mathrm{P}) \mathrm{H}$-dependent enzymes, ${ }^{14}$ iii) the enhancement of the catalytic activity of selected NADH-dependent enzymes and iv) orthogonality against NADH as a limited number of enzymes accept $\operatorname{mNAD}(\mathrm{H})$ as cofactor (Scheme 1). ${ }^{14-20}$ Simple mNADHs 1-5 (Scheme 1) might however suffer from various disadvantages, foremost the limited number of enzymes that accept them as redox equivalents. Further potential drawbacks include low solubility of the reduced form of the mimic and reduced chemical stability, if the mimics are electronically very different from natural NAD $(\mathrm{P}) \mathrm{H}$.

For in situ NAD(P)H regeneration, enzymes, such as alcohol dehydrogenases, glucose dehydrogenases and phosphite dehydrogenase, have been widely utilized. ${ }^{21,22}$ However, these enzymatic methods cannot be applied to $\mathrm{mNAD}^{+} \mathrm{s}$, as these do not accept mNAD ${ }^{+}$as a substrate (see iv) above). Recently an in situ catalytic reduction of $\mathrm{mNAD}^{+}$by a rhodium complex was reported, albeit at the cost of a low TTN. ${ }^{19}$ To date, only few studies report the in situ regeneration of mNADHs which, has hampered their widespread use as redox mediators. ${ }^{14,16,23-27}$ Regeneration challenges typically include: i) deactivation of the enzymatic partners and/or organometallic regeneration catalyst as well as ii) low productivity, selectivity and initial activity. ${ }^{28-33}$ The very limited success in mNADH regeneration severely hampers their widespread use and application.

In the past decade, artificial metalloenzymes (AMEs) have attracted attention as an alternative to both homogeneous catalysts and enzymes. ${ }^{34-43}$ In this context we have shown that artificial transfer hydrogenases (ATHases) based on an abiotic biotinylated Ir-pianostool cofactor, IrC (Scheme 1c) and streptavidin variants, provide an attractive solution to the incompatibility of synthetic transition metal catalysts and enzymes. ${ }^{44-51}$ Cascade reactions of ATHases with a range of different enzymes, namely a flavin dependent monooxygenase, heme dependent enzymes (catalase and peroxidase), a flavin dependent amine oxidase and amino acid oxidases were realized. ${ }^{52}$ Since ATHases can reduce $\mathrm{NAD}(\mathrm{P})^{+},{ }^{+52,53}$ we set out to explore the versatility of ATHases towards the regeneration of $\mathrm{mNAD}^{+} \mathrm{s}$.

As an mNADH-accepting enzyme, the ene reductase (ER) of the Old Yellow Enzyme family from Thermus scotuductus (Ts OYE) was selected. ${ }^{14,54}$ Compared to the use of $\mathrm{NAD}(\mathrm{P}) \mathrm{H}$, similar or even higher initial rates and conversions have been reported for reactions involving stoichiometric amounts of the mimic 1 in the presence of TsOYE. ${ }^{14,19}$ ATHases were generated by employing a $1: 2$ ratio of the biotinylated cofactor and biotin binding sites. ${ }^{55}$ As a stoichiometric reducing agent, sodium formate was selected (Scheme 1a). To identify an efficient regeneration system for the reduction of $\mathrm{N}$-ethyl-2methylmaleimide 6 (Scheme 2) with TsOYE, five different $\mathrm{NAD}^{+}$mimics 1-5 (Scheme 1b) were screened in combination with the biotinylated Ir-cofactor IrC and a range of Sav variants. Previous studies with the ATHase have revealed that mutations at three close lying positions (i.e. S112, K121 and L124) have a significant impact on the catalysis outcome (Scheme 1c). ${ }^{56}$ 
a)

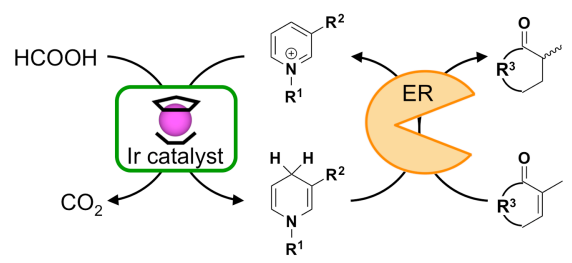

b)

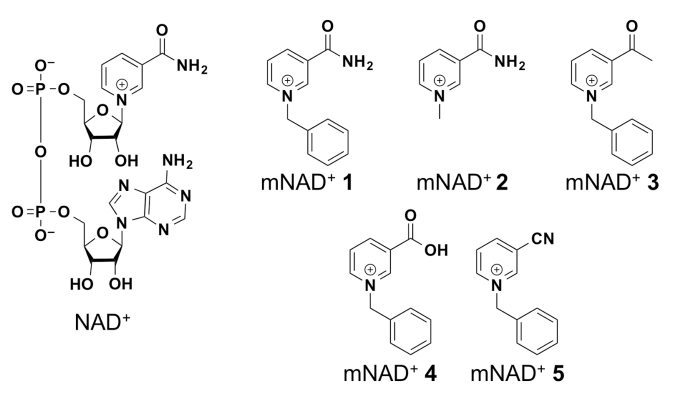

c)

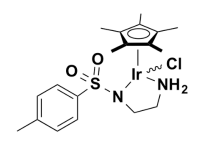

IrA
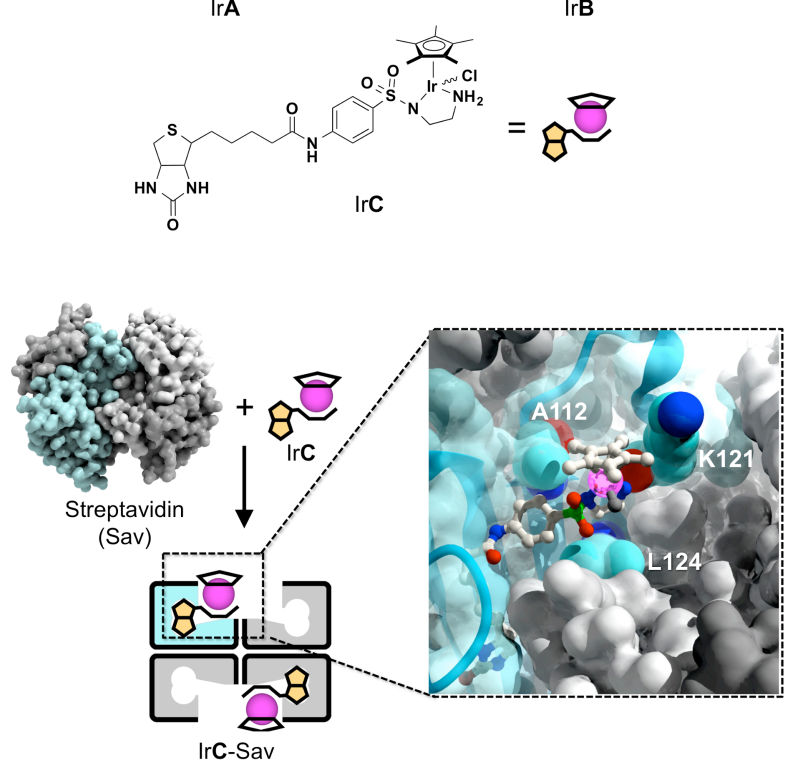

Scheme 1. (a) Catalytic reduction of Michael acceptors by ene reductase (ER) and concurrent catalytic cofactor regeneration by IrCp* complexes. (b) Nicotinamide mimics 1-5 $\left(\mathrm{mNAD}^{+}\right)$tested as cofactors in this study. (c) $\operatorname{IrCp}$ * complexes (IrA-C) and artificial transfer hydrogenase (IrC-Sav) tested for the reduction of $\mathrm{mNAD}^{+}{ }^{1-5}$. Inset: close-up view of the structure of IrC-Sav S112A variant (PDB ID: 3PK2).

Although higher initial rates for $\mathrm{mNAD}^{+} \mathbf{1}$ reduction were observed under acidic conditions (Table S2), the $\mathrm{pH}$ of the reaction was set to 7.0. This value constitutes a trade-off between the $\mathrm{pH}$-dependence of the ATHase activity and the mNADH stability (Figure S1). Furthermore, a neutral pH provides sufficient hydrolytic stability of the maleimide $\mathbf{6}$ used as a model substrate. ${ }^{57,58}$ No significant influence of formate on the activity of $T s$ OYE was observed (Figure S2). For the screening, both the biotinylated Ir-cofactor IrC as well as nonbiotinylated analogues $\operatorname{Ir} \mathbf{A}$ and $\operatorname{Ir} \mathbf{B}$ were included as catalysts (Scheme 1c).

The fingerprint display summary (Scheme 2, Table S3) highlights the following features: a) mNADH 3 showed best performance in terms of enantioselectivity and GC-yield; b) four of the Sav variants with mNAD ${ }^{+} \mathbf{3}$ provided higher GCyield and comparable activity to the protein-free cofactor $\operatorname{IrC}$ or its non-biotinylated analogues $\operatorname{Ir} \mathbf{A}$ and $\operatorname{Ir} \mathbf{B}$; the best suited Sav variant is mutant $\mathrm{S} 112 \mathrm{~K}$, providing over two-fold improvement compared to the protein-free Ir complexes.; c) while it has been previously shown that stoichiometric amounts of mNADH 1 combined with TsOYE leads to the best GC-yield, ${ }^{14}$ the mimic mNADH 3 proved most suitable (both in terms of e.e. and GC-yield) for the cascade including the Ir-based ATHase regeneration system (Figure S3) $)^{9,59,60}$ and d) the nature of the mNADH plays a critical role in determining the e.e. of the reduction product 7 . We assume that the last point is due to the relative rates of reduction of $\mathrm{mNAD}^{+} \mathbf{1}$ 5 vs. substrate 6 by the ATHase (vide infra). ${ }^{14}$

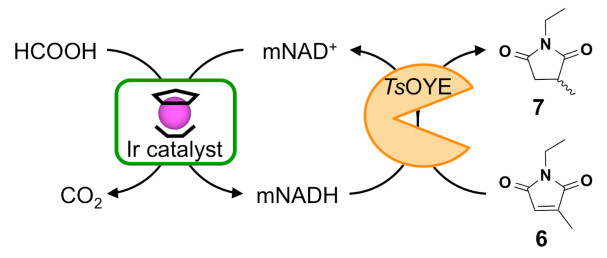

\begin{tabular}{|c|c|c|c|c|c|c|c|}
\hline & & & NAD & & & vield [\%]' & e.e. [\%] \\
\hline & 1 & 2 & & 4 & 5 & 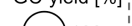 & \\
\hline IrA & 0 & o & & 0 & o & 100 & $90(R)$ \\
\hline IrB & 0 & $\circ$ & & o & 0 & 90 & 80 \\
\hline IrC & 0 & o & & 0 & $\circ$ & 80 & 70 \\
\hline IrC-WT & 0 & 0 & & 0 & $\circ$ & 70 & 60 \\
\hline IrC-S112A & & 0 & & 0 & $\circ$ & 60 & 50 \\
\hline IrC-S112K & & 0 & & 0 & 0 & 50 & 40 \\
\hline IrC-S112R & 0 & o & & 0 & 0 & 40 & 30 \\
\hline IrC-S112T & & 0 & & 0 & 0 & 30 & 20 \\
\hline $\mathrm{IrC}-\mathrm{K} 121 \mathrm{~A}$ & & O & & O & $\circ$ & $\bigcirc \quad 20$ & 10 \\
\hline IrC-K121R & O & O & & 0 & ○ & O 10 & 0 \\
\hline IrC-L124K & 0 & ○ & 0 & 0 & $\circ$ & 0 & 10 \\
\hline IrC-L124F & 0 & $\circ$ & 0 & 0 & - & & $20(S)$ \\
\hline
\end{tabular}

Scheme 2. Fingerprint display of the GC-yield and e.e. for $\mathrm{N}$-ethyl-2-methylmaleimide 6 reduction by TSOYE / mNADHs 1-5 and IrCp* / HCOOH based regeneration system. $10 \mu M$ catalyst (IrCp*), $0.5 \mathrm{mg} / \mathrm{ml}(3 \mu \mathrm{M}) T \mathrm{~s} O Y E$, $1 \mathrm{mM} \mathrm{mNAD}^{+}, 10 \mathrm{mM} N$-ethyl-2-methylmaleimide 6 , and 2.0 M HCOONa in 0.6 M MOPS (pH 7.0); experiments were performed at $30{ }^{\circ} \mathrm{C}$ for $4 \mathrm{~h}$ on a $400 \mu \mathrm{l}$ scale. GCyield and enantiomeric excess (e.e.) were determined by GC with benzyl alcohol as internal standard; GC-yields are based on product formation.

In order to evaluate the inactivation of the Ir-based regeneration catalyst in the presence of $T_{s} \mathrm{OYE}$, the initial rate of mNAD ${ }^{+} \mathbf{3}$ reduction was determined spectrophotometrically (Figure S4). The initial rate for the protein-free cofactor $\mathrm{IrC}$ is about 1.6 fold faster than for the best ATHase IrC-Sav S112K. 
However, in the presence of the $T s \mathrm{OYE}$, the relative activity is reversed: the protein-free cofactor IrC looses over $80 \%$ of its initial activity. In stark contrast, it maintains over $80 \%$ of its activity when incorporated into Sav S112K (Figure 1). The Ts OYE maintains its activity in the presence of either $\operatorname{IrC}$ or IrC-Sav112K (Figure S5).
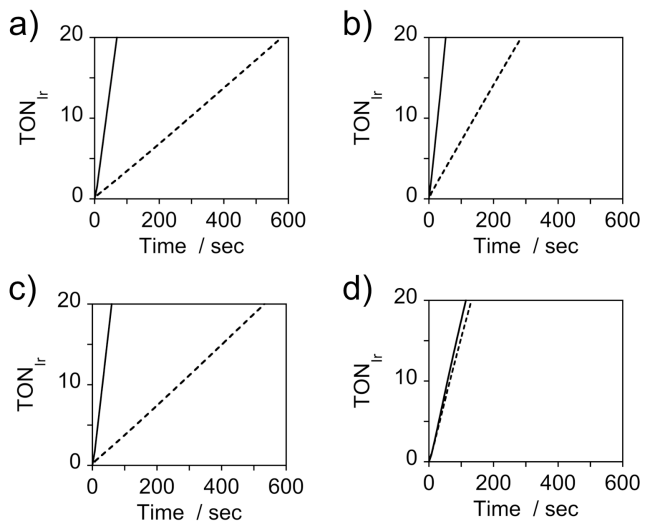

Figure 1. Initial rates of $m \mathrm{NAD}^{+} \mathbf{3}$ reduction catalyzed by (a) $\operatorname{Ir} \mathbf{A}$, (b) $\operatorname{IrB}$, (c) IrC, and (d) IrC-Sav S112K in the absence (solid line) and in the presence of TsOYE (dashed line) monitored by UV-vis absorption at $378 \mathrm{~nm}$. $10 \mu \mathrm{M}$ Ir-catalyst, $0.5 \mathrm{mg} / \mathrm{ml}(3 \mu \mathrm{M})$ Ts OYE, $1 \mathrm{mM} \mathrm{mNAD}{ }^{+} 3$, and $2.0 \mathrm{M} \mathrm{HCOONa}$ in 0.6 M MOPS (pH 7.0); experiments were performed at $25^{\circ} \mathrm{C}$.

After identifying the combination of $\mathrm{mNAD}^{+} \mathbf{3}, \mathrm{IrC}$ and Sav $\mathrm{S} 112 \mathrm{~K}$ as the most efficient artificial cofactor regeneration system, it was compared with the established regeneration method for reducing equivalents comprised of $\mathrm{NAD}(\mathrm{P})^{+}, \mathrm{GDH}$ and glucose (1.2 mg of GDH per $\mathrm{ml})$. Ts $\mathrm{OYE}$ mediated reduc- tion coupled to the mNAD ${ }^{+}$3-ATHase system $(10 \mu \mathrm{M}, 1.2 \mathrm{mg}$ of Sav per ml) gave higher GC-yield than with the $\mathrm{NAD}^{+}-$ GDH system at the cost of a slightly eroded enantioselectivity (Table 1 , entries 1,10$)$. In combination with the $\mathrm{NADP}^{+}-\mathrm{GDH}$ system however, it outperformed both regeneration with mNAD $^{+}$3-ATHase or with NAD ${ }^{+}-$GDH (Table 1 , entry 2$) .{ }^{14}$ Regeneration of NADH or NADPH with the ATHase led to low GC-yield and nearly racemic product 7 , suggesting that the $N$-ethyl-2-methylmaleimide $\mathbf{6}$ is a better substrate than $\mathrm{NAD}(\mathrm{P})^{+}$for the ATHase (Table 1 , entries 8,9$)$ leading to its direct (racemic) reduction by the $\{\mathrm{Ir}-\mathrm{H}\}$-moiety.

To alleviate the erosive effect of the direct substrate (6) reduction on enantioselectivity of the cascade process, the loading of mNAD 3 was set to $10 \mathrm{~mol} \%$ - resulting in an e.e. of 91-93\% (see Table S4). Gratifyingly, a set of alternative ERs (from Codexis) also readily accepted mimic $\mathbf{3}$ and were tested in the cascade reaction. Except for ERED-P1-E01, none of these compared favorably with Ts OYE, (Table S5).

Upon increasing the reaction time from four to seven hours, the initial loading of iridium could be reduced from the $0.1 \%$ to $0.05 \%$ without compromising the GC-yield (Table 1, entries $10,11)$. Slow addition of the substrate allowed to improve the e.e. further (up to $95-98 \%$ e.e.) by minimizing the background direct reduction of substrate 6 (Table 1, entries 11, 12). A preparative scale reaction with $N$-ethyl-2-methylmaleimide 6 (1.0 mmol) resulted in $>99 \%$ GC-yield (61\% isolated yield) and $98 \%$ e.e. (Table 1 , entry 13 ).

Ketoisophorone 8 and 2-methylcyclohexenone 9 were reduced with moderate to good GC-yields when applied to the cascade (Table 1, entries 14-19). The lower enantioselectivity for the reduction of $\mathbf{8}$ reflects the trend observed in reactions with stoichiometric quantities of cofactor and is partly due to a known non-enzymatic racemization of the reduced product over time. ${ }^{14,61}$

Table 1. Selected results for ERs using mNAD ${ }^{+} 3$. $^{a}$

\begin{tabular}{|c|c|c|c|c|c|c|c|c|c|}
\hline Entry & ER & $\begin{array}{c}\mathrm{IrC}-\mathrm{S} 112 \mathrm{~K} \\
{[\mathrm{~mol} \%]}\end{array}$ & $(\mathrm{m}) \mathrm{NAD}(\mathrm{P})^{+}$ & Substrate & $\begin{array}{c}\text { Time } \\
{[\mathrm{h}]}\end{array}$ & $\begin{array}{l}\text { e.e. } \\
{[\%]}\end{array}$ & $\begin{array}{c}\text { GC-yield } \\
{[\%]}\end{array}$ & $\mathrm{TTN}_{\mathrm{Ir}}$ & $\mathrm{TTN}_{\mathrm{ER}}{ }^{h}$ \\
\hline 1 & $T s \mathrm{OYE}$ & $\mathrm{GDH}^{b}$ & $\mathrm{NAD}^{+}$ & 6 & 4 & $>99(R)$ & 65 & $195^{g}$ & 118 \\
\hline 2 & $T_{s} \mathrm{OYE}$ & $\mathrm{GDH}^{b}$ & NADP $^{+}$ & 6 & 4 & $>99(R)$ & $>99$ & $>298^{g}$ & 181 \\
\hline 3 & - & $0.1(\operatorname{Ir} \mathbf{A})^{c}$ & - & 6 & 4 & 0 & 10 & 104 & 80 \\
\hline 4 & - & $0.1(\operatorname{Ir} \mathbf{B})^{c}$ & - & 6 & 4 & $2(R)$ & 5 & 5 & 4 \\
\hline 5 & - & $0.1(\operatorname{IrC})^{c}$ & - & 6 & 4 & 0 & 10 & 96 & 74 \\
\hline 6 & - & 0.1 & - & 6 & 4 & $3(S)$ & 14 & 136 & 105 \\
\hline 7 & $T s \mathrm{OYE}$ & 0.1 & - & 6 & 4 & $4(S)$ & 11 & 113 & 374 \\
\hline 8 & $T s \mathrm{OYE}$ & 0.1 & $\mathrm{NAD}^{+}$ & 6 & 4 & $4(R)$ & 12 & 117 & 390 \\
\hline 9 & $T s \mathrm{OYE}$ & 0.1 & $\mathrm{NADP}^{+}$ & 6 & 4 & $6(R)$ & 14 & 139 & 464 \\
\hline 10 & $T s \mathrm{OYE}$ & 0.1 & $\mathrm{mNAD}^{+} \mathbf{3}$ & 6 & 4 & $93(R)$ & 85 & 853 & 2843 \\
\hline 11 & $T s \mathrm{OYE}$ & 0.05 & $\mathrm{mNAD}^{+} \mathbf{3}$ & 6 & 7 & $91(R)$ & 87 & 1746 & 8730 \\
\hline
\end{tabular}




\begin{tabular}{|c|c|c|c|c|c|c|c|c|c|}
\hline 12 & $T s \mathrm{OYE}$ & 0.05 & $\mathrm{mNAD}^{+} \mathbf{3}$ & 6 & $7^{d}$ & $95(R)$ & $>99$ & $>1980$ & $>9900$ \\
\hline 13 & $T_{S} \mathrm{OYE}$ & 0.05 & $\mathrm{mNAD}^{+} \mathbf{3}$ & 6 & $7^{e}$ & $98(R)$ & $>99(61)^{f}$ & $>1980$ & $>9900$ \\
\hline 14 & Ts OYE & 0.05 & $\mathrm{mNAD}^{+} \mathbf{3}$ & 8 & 8 & $86(R)$ & 30 & 556 & 2980 \\
\hline 15 & Ts OYE & 0.05 & $\mathrm{mNAD}^{+} \mathbf{3}$ & 8 & $8^{d}$ & $85(R)$ & 23 & 467 & 2333 \\
\hline 16 & Ts OYE & 0.05 & $\mathrm{mNAD}^{+} \mathbf{3}$ & 8 & 24 & $72(R)$ & 48 & 951 & 4756 \\
\hline 17 & Ts OYE & 0.05 & $\mathrm{mNAD}^{+} \mathbf{3}$ & 9 & 8 & $94(R)$ & 69 & 1385 & 6531 \\
\hline 18 & $T_{s} \mathrm{OYE}$ & 0.05 & $\mathrm{mNAD}^{+} \mathbf{3}$ & 9 & $8^{d}$ & $94(R)$ & 69 & 1369 & 6457 \\
\hline 19 & $T_{s} \mathrm{OYE}$ & 0.05 & $\mathrm{mNAD}^{+} \mathbf{3}$ & 9 & 12 & $82(R)$ & 83 & 1655 & 7799 \\
\hline
\end{tabular}

${ }^{a}$ Experiments were performed in 0.6 M MOPS, $2.0 \mathrm{M} \mathrm{HCOONa}(\mathrm{pH} 7.0)$ at $30{ }^{\circ} \mathrm{C}$ and on a $400 \mu \mathrm{l}$ scale (except entry 13$) ; 10 \mathrm{mM}(\mathrm{entries}$ 1-10) or $30 \mathrm{mM}$ (entries 11-19) substrate, $3 \mu \mathrm{M}$ Ts OYE, $1 \mathrm{mM}$ (entry 10) or $3 \mathrm{mM}$ (entries 11-19) mNAD 3 or 1 mM NAD(P) ${ }^{+}($entries 1 , $2,8,9$ ). Average values for triplicate reactions are shown (except for entry 13 ); standard deviations were $\leq 1.4 \%$. GC-yields were determined by GC with the following internal standards: benzyl alcohol for $\mathbf{6}$, cyclohexanol for ketoisophorone (8) and 2-methylcyclohexenone (9). Absolute configuration of 7 was tentatively assigned by comparison with $N$-phenyl-3-methylsuccinimide produced by $T s \mathrm{OYE}$ reduction. ${ }^{14}$ The absolute configuration of reduced $\mathbf{8}$ (levodione 10) by TsOYE reduction has been reported previously. ${ }^{14}$ Absolute configuration of reduced 9 (2-methylcyclohexanone 11) was tentatively assigned by optical rotation and comparison with literature data (see SI). ${ }^{b} 1.2$ $\mathrm{mg} / \mathrm{ml}$ of glucose dehydrogenase (GDH-105 from Codexis) and $100 \mathrm{mM}$ glucose were used instead of ATHase IrC-Sav S112K and HCOONa. ${ }^{c}$ IrA, IrB, and IrC were used instead of IrC-S112K, respectively. ${ }^{d}$ Half of the substrate was added at $0 \mathrm{~h}$ and after $1 \mathrm{~h}$, respectively. ${ }^{e}$ Preparative scale reaction, $141 \mathrm{mg}$ of $\mathbf{6}$ was added to the reaction mixture in portions every 10 min for 170 min. ${ }^{f}$ isolated yield. ${ }^{g}$ An accurate turnover number for the commercial GDH can not be calculated, since the enzyme is only semipurified according to the manufacturer. We calculated an upper limit based on $78 \%$ purity (determined by the Bradford assay) ${ }^{62}$ and a molecular weight of $28 \mathrm{kDa} .{ }^{63,64}$ The reaction conditions have not been optimized for GDH. Alternative enzymes with potentially higher activity (e.g. Codexis CDX-901) are commercially available. ${ }^{h}$ TTNs for $T s$ OYE represent a lower limit based on protein content in the lyophilised preparation (20 wt $\left.\%\right)$ as determined

by

the

Bradford

assay.

In summary, the first efficient regeneration system for NADH mimics has been developed and its applicability demonstrated in the combination with a range of ene reductases. Further research will focus on the evaluation in concurrent reactions with other enzymes that accept mimics such as monooxygenases. ${ }^{18}$ To the best of our knowledge, the catalytic performance (i.e. TTN) of this Ir-based system for (m)NADH regeneration is the best reported for non-enzymatic regeneration systems. Potential regeneration systems for $\mathrm{mNAD}^{+} \mathrm{s}$ will have to be scrutinized with respect to achievable turnover frequency and total turnover number not only for the regenerating metal catalyst, but also for the mimic.

\section{ASSOCIATED CONTENT}

\section{Supporting Information}

The Supporting Information is available free of charge on the ACS Publications website. The supporting information include follows; materials, instruments, buffers and stock solutions for the enzymatic reactions, experimental procedures, GC analysis conditions and their representative chromatogram, the comparison of catalytic activities of $\operatorname{IrC}$ and ATHase variants for $\mathrm{mNAD}^{+} \mathbf{1}$ reduction, the stability of $\mathrm{mNAD}^{+} \mathbf{1}$, the influence of formate on the activity of the $T s \mathrm{OYE}$, the numerical values for the fingerprint displayed in Scheme 2, the comparison of the reduction rates of $\mathrm{mNAD}^{+} \mathbf{1}$ and $\mathrm{mNAD}^{+} \mathbf{3}$ vs $\mathrm{NAD}(\mathrm{P})^{+}$by the ATHase variant $\mathrm{S} 112 \mathrm{~K}$, the spectral changes of the reduction of $\mathrm{mNAD}^{+} \mathbf{3}$ to mNADH 3, the influence of the iridium cofactor IrC and ATHase $\mathrm{S} 112 \mathrm{~K}$ on $T s \mathrm{OYE}$, the optimization of reaction condition for the cascade reactions, ${ }^{1} \mathrm{H}-\mathrm{NMR}$ and ${ }^{13} \mathrm{C}-\mathrm{NMR}$ of the $\mathrm{N}$-ethyl-2methylsucccine imide obtained in the preparative cascade reactions (PDF)

\section{AUTHOR INFORMATION}

\section{Corresponding Author}

*E-mail for T. R.W.; thomas.ward@unibas.ch

\section{Author Contributions}

FH, VK and TRW designed the project, YO and CEP designed and performed the experiments and analyzed the results. YO, VK and TRW wrote the manuscript.

\section{Funding Sources}

Generous support from the Swiss National Science Foundation (grant 200020_162348) and from the NCCR Molecular Systems Engineering is gratefully acknowledged.

\section{ACKNOWLEDGMENT}

We thank PD Dr. D. Häussinger for help with the interpretation of NMR spectra.

\section{ABBREVIATIONS}

mNADH, NAD(P)H mimic; Sav, streptavidin; AME, artificial metalloenzyme; ATHase, artificial transfer hydrogenase; ER, ene reductase; Ts OYE, the Old Yellow Enzyme family from Thermus scotuductus.

\section{REFERENCES}

(1) Schmid, A.; Dordick, J. S.; Hauer, B.; Kiener, A.; Wubbolts, M.; Witholt, B. Nature 2001, 409, 258-268.

(2) Straathof, A. J. J.; Panke, S.; Schmid, A. Curr. Opin. Biotechnol. 2002, 13, 548-556.

(3) Schrittwieser, J. H.; Sattler, J.; Resch, V.; Mutti, F. G.; Kroutil, W. Curr. Opin. Chem. Biol. 2011, 15, 249-256. 
(4) Patel, R. N. ACS Catal. 2011, 1, 1056-1074.

(5) Bornscheuer, U. T.; Huisman, G. W.; Kazlauskas, R. J.; Lutz, S.; Moore, J. C.; Robins, K. Nature 2012, 485, 185-194.

(6) Turner, N. J.; Truppo, M. D. Curr. Opin. Chem. Biol. 2013, $17,212-214$

(7) Reetz, M. T. J. Am. Chem. Soc. 2013, 135, 12480-12496.

(8) Shaked, Z.; Whitesides, G. M. J. Am. Chem. Soc. 1980, 102, 7104-7105

(9) Gebicki, J.; Marcinek, A.; Zielonka, J. Acc. Chem. Res. 2004, 37, 379-386.

(10) Hall, M.; Bommarius, A. S. Chem. Rev. 2011, 111, 40884110.

(11) Anderson, B. M.; Kaplan, N. O. J. Biol. Chem. 1959, 234, $1226-1232$

(12) Yasui, S.; Ohno, A. Bioorg. Chem. 1986, 14, 70-96.

(13) McSkimming, A.; Colbran, S. B. Chem. Soc. Rev. 2013, 42 , $5439-5488$.

(14) Paul, C. E.; Gargiulo, S.; Opperman, D. J.; Lavandera, I.; Gotor-Fernández, V.; Gotor, V.; Taglieber, A.; Arends, I. W. C. E.; Hollmann, F. Org. Lett. 2013, 15, 180-183.

(15) Kazlauskas, R. J. J. Org. Chem. 1988, 53, 4633-4635.

(16) Lutz, J.; Hollmann, F.; Ho, T. V.; Schnyder, A.; Fish, R. H.; Schmid, A. J. Organomet. Chem. 2004, 689, 4783-4790.

(17) Paul, C. E.; Arends, I. W. C. E.; Hollmann, F. ACS Catal. 2014, 4, 788-797.

(18) Paul, C. E.; Tischler, D.; Riedel, A.; Heine, T.; Itoh, N.; Hollmann, F. ACS Catal. 2015, 5, 2961-2965.

(19) Knaus, T.; Paul, C. E.; Levy, C. W.; de Vries, S.; Mutti, F. G.; Hollmann, F.; Scrutton, N. S. J. Am. Chem. Soc. 2016, 138, 10331039.

(20) Paul, C. E.; Churakova, E.; Maurits, E.; Girhard, M.; Urlacher, V. B.; Hollmann, F. Bioorg. Med. Chem. 2014, 22, 56925696.

(21) Johannes, T. W.; Woodyer, R. D.; Zhao, H. Biotechnol. Bioeng. 2007, 96, 18-26.

(22) Kara, S.; Schrittwieser, J. H.; Hollmann, F.; AnsorgeSchumacher, M. B. Appl. Microbiol. Biotechnol. 2014, 98, 15171529.

(23) Wagenknecht, P. S.; Penney, J. M.; Hembre, R. T. Organometallics 2003, 22, 1180-1182.

(24) Gaillard, S.; Papamicaël, C.; Marsais, F.; Dupas, G.; Levacher, V. Synlett 2005, 2005, 441-444.

(25) Ji, D.; Wang, L.; Hou, S.; Liu, W.; Wang, J.; Wang, Q.; Zhao, Z. K. J. Am. Chem. Soc. 2011, 133, 20857-20862.

(26) Jones, D. P.; Sies, H. Antioxid. Redox Signal. 2015, 23, 734-746.

(27) Lo, H. C.; Buriez, O.; Kerr, J. B.; Fish, R. H. Angew. Chem. Int. Ed. 1999, 38, 1429-1432.

(28) Lo, H. C.; Leiva, C.; Buriez, O.; Kerr, J. B.; Olmstead, M. M.; Fish, R. H. Inorg. Chem. 2001, 40, 6705-6716.

(29) Hollmann, F.; Hofstetter, K.; Schmid, A. Trends Biotechnol. 2006, 24, 163-171.

(30) Hollmann, F.; Arends, I. W. C. E.; Buehler, K. ChemCatChem 2010, 2, 762-782.

(31) Wu, H.; Tian, C.; Song, X.; Liu, C.; Yang, D.; Jiang, Z. Green Chem. 2013, 15, 1773-1789.

(32) Quinto, T.; Köhler, V.; Ward, T. R. Top. Catal. 2013, 57, 321-331.

(33) de Torres, M.; Dimroth, J.; Arends, I. W. C. E.; Keilitz, J.; Hollmann, F. Molecules 2012, 17, 9835-9841.

(34) Wilson, M. E.; Whitesides, G. M. J. Am. Chem. Soc. 1978 100, 306-307.

(35) Yu, F.; Cangelosi, V. M.; Zastrow, M. L.; Tegoni, M.; Plegaria, J. S.; Tebo, A. G.; Mocny, C. S.; Ruckthong, L.; Qayyum, H.; Pecoraro, V. L. Chem. Rev. 2014, 114, 3495-3578.

(36) Ueno, T.; Abe, S.; Yokoi, N.; Watanabe, Y. Coord. Chem. Rev. 2007, 251, 2717-2731

(37) Hayashi, T.; Sano, Y.; Onoda, A. Isr. J. Chem. 2014, 55, $76-84$.

(38) Lewis, J. C. Cur. Opin. Chem. Biol. 2015, 25, 27-35.
(39) Deuss, P. J.; den Heeten, R.; Laan, W.; Kamer, P. C. J. Chem. Eur. J. 2011, 17, 4680-4698.

(40) Matsuo, T.; Hirota, S. Bioorg. Med. Chem. 2014, 22, 5638 5656.

(41) Pàmies, O.; Diéguez, M.; Bäckvall, J. Adv. Synth. Catal. 2015, 357, 1567-1586.

(42) Bos, J.; Roelfes, G. Curr. Opin. Chem. Biol. 2014, 19, 135143.

(43) Lu, Y. Curr. Opin. Chem. Biol. 2005, 9, 118-126.

(44) For recent reviews on combined chemo/biocatalysis and pertaining compatibility issues see Ref 45-47.

(45) Gröger, H.; Hummel, W. Curr. Opin. Chem. Biol. 2014, 19, 171-179.

(46) Denard, C. A.; Hartwig, J. F.; Zhao, H. ACS Catal. 2013, 3, 2856-2864.

(47) Köhler, V.; Turner, N. J. Chem. Commun. 2015, 51, 450464.

(48) Abril, O.; Whitesides, G. M. J. Am. Chem. Soc. 1982, 104, $1552-1554$.

(49) Yan, Y. K.; Melchart, M.; Habtemariam, A.; Peacock, A. F A.; Sadler, P. J. J. Biol. Inorg. Chem. 2006, 11, 483-488.

(50) Soldevila-Barreda, J. J.; Romero-Canelón, I.; Habtemariam, A.; Sadler, P. J. Nat. Commun. 2015, 6, 6582.

(51) Maenaka, Y.; Suenobu, T.; Fukuzumi, S. J. Am. Chem. Soc. 2012, 134, 9417-9427.

(52) Köhler, V.; Wilson, Y. M.; Dürrenberger, M.; Ghislieri, D.; Churakova, E.; Quinto, T.; Knörr, L.; Häussinger, D.; Hollmann, F.; Turner, N. J.; Ward, T. R. Nat. Chem. 2013, 5, 93-99.

(53) Quinto, T.; Häussinger, D.; Köhler, V.; Ward, T. R. Org. Biomol. Chem. 2015, 13, 357-360.

(54) Opperman, D. J.; Sewell, B. T.; Litthauer, D.; Isupov, M. N.; Littlechild, J. A.; van Heerden, E. Biochem. Biophys. Res. Commun. 2010, 393, 426-431.

(55) Robles, V. M.; Dürrenberger, M.; Heinisch, T.; Lledós, A.; Schirmer, T.; Ward, T. R.; Marechal, J.-D. J. Am. Chem. Soc. 2014, 136, 15676-15676.

(56) Dürrenberger, M.; Heinisch, T.; Wilson, Y. M.; Rossel, T.; Nogueira, E.; Knörr, L.; Mutschler, A.; Kersten, K.; Zimbron, M. J.; Pierron, J.; Schirmer, T.; Ward, T. R. Angew. Chem. Int. Ed. 2011, 50, 3026-3029.

(57) Machida, M.; Machida, M. I.; Kanaoka ,Y. Chem. Pharm. Bull. 1977, 25, 2739-2743.

(58) Matsui, S.; Aida, H. J. Chem. Soc., Perkin Trans. 2 1978, $1277-1280$.

(59) Gebicki, J.; Marcinek, A.; Adamus, J.; Paneth, P.; Rogowski, J. J. Am. Chem. Soc. 1996, 118, 691-692.

(60) Gebicki, J.; Bally, T. Acc. Chem. Res. 1997, 30, 477-485.

(61) Fryszkowska, A.; Toogood, H.; Sakuma, M.; Gardiner, J. M.; Stephens, G. M.; Scrutton, N. S. Adv. Synth. Catal. 2009, 351, 2976-2990.

(62) Bradford, M. M. Anal. Biochem. 1976, 72, 248-254

(63) Davis, S.; Jenne, S.; Krebber, A.; Newman, L. Glucose dehydrogenase polypeptide and related polynucleotides. U.S. Patent 20050095619, May 5, 2005.

(64) Lampel, K. A.; Uratani, B.; Chaudhry, G. R.; Ramaley, R. F.; Rudikoff, S. J. Bacteriol. 1986, 166, 238-243. 


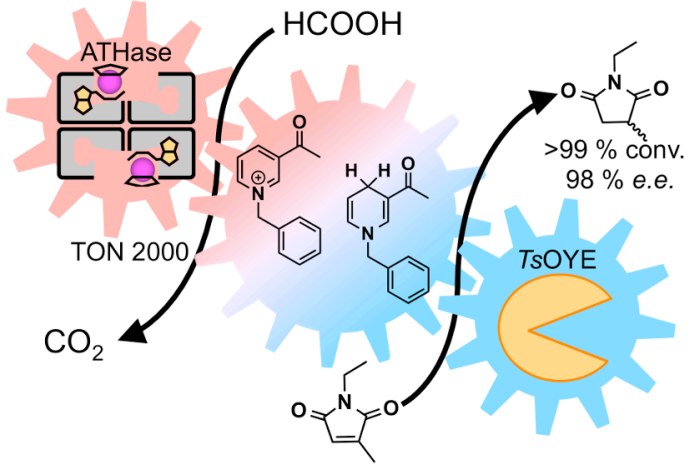

